\title{
Hydrometallurgical Synthesis of Nickel Nano-Sulfides from Spent Lithium-Ion Batteries
}

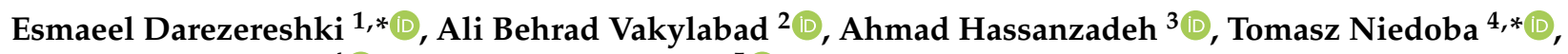 \\ Agnieszka Surowiak $^{4}$ (D) and Babak Koohestani ${ }^{5}$ (D) \\ 1 Department of Materials Engineering, Shahid Bahonar University of Kerman, Kerman 76169-133, Iran \\ 2 Department of Materials, Institute of Science and High Technology and Environmental Sciences, \\ Graduate University of Advanced Technology, Kerman 76315-117, Iran; alibehzad86@yahoo.co.uk \\ 3 Independent Scholar, Am Apostelhof 7A, 50226 Frechen, Germany; a.hassanzadeh@gmx.de \\ 4 Department of Environmental Engineering, Faculty of Mining and Geoengineering, AGH University of \\ Science and Technology, al. Mickiewicza 30, 30-059 Krakow, Poland; asur@agh.edu.pl \\ 5 Mining and Mineral Processing Department, Tarbiat Modares University, Tehran 14155-6343, Iran; \\ b.koohestani@modares.ac.ir \\ * Correspondence: darezereshki@uk.ac.ir (E.D.); tniedoba@agh.edu.pl (T.N.); Tel.: +48-126-172-056 (T.N.)
}

Citation: Darezereshki, E.

Vakylabad, A.B.; Hassanzadeh, A.; Niedoba, T.; Surowiak, A.;

Koohestani, B. Hydrometallurgical Synthesis of Nickel Nano-Sulfides from Spent Lithium-Ion Batteries. Minerals 2021, 11, 419. https:// doi.org/10.3390/min11040419

Academic Editor: Benjamin P. Wilson

Received: 19 March 2021

Accepted: 13 April 2021

Published: 15 April 2021

Publisher's Note: MDPI stays neutral with regard to jurisdictional claims in published maps and institutional affiliations.

Copyright: (c) 2021 by the authors. Licensee MDPI, Basel, Switzerland. This article is an open access article distributed under the terms and conditions of the Creative Commons Attribution (CC BY) license (https:// creativecommons.org/licenses/by/ $4.0 /)$.
Abstract: By developing technologies, spent lithium-ion batteries (LIBs) are considered a great source of nickel-cobalt ions to fabricate metal sulfide nanoparticles. However, the presence of unnecessary ions such as manganese and lithium may hamper the formation of pure metal sulfide nanostructures where the utilization of proper ligand(s) can be very critical. For this reason, the present study initially introduces a promising and cost-effective acidic leaching followed by precipitation and thermal treatment $\left(\sim 250^{\circ} \mathrm{C}, 1 \mathrm{~h}\right)$ processes to fabricate pure NiS nanopowders from the LIBs, while considering potassium amyl xanthate as the precipitating agent. The produced nanoparticle's size and structure were characterized by commonly used and advanced analytical techniques such as X-ray diffraction (XRD), scanning electron microscopy (SEM), transmission electron microscopy (TEM) and photon correlation spectroscopy (PCS), and inductively coupled plasma optical emission spectrometry (ICP-OES). The elemental distributions and functional groups were analyzed through energy dispersive X-ray spectroscopy (EDS) and Fourier-transform infrared spectroscopy (FTIR) methods. The characteristic analyses of the spherical-like NiS particles showed a mean particle size of $61 \pm 2 \mathrm{~nm}$ (by TEM) and $64 \mathrm{~nm}$ (through the PCS method) with high purities approved via XRD and EDS analyses. Moreover, comparing the obtained XRD data with the standard ones showed a perfect match with the hexagonal structure of the NiS phase. We finally concluded that such a presented approach is very practical and efficient for converting the LIBs to an extremely valuable product. Future studies are suggested for the fundamental conceptualization of the processes.

Keywords: nanoparticles; xanthate; metal sulfide; lithium-ion batteries; nickel; cobalt

\section{Introduction}

The annual production of lithium-ion batteries (LIBs) has considerably augmented due to the sharp increase in growth of electric vehicles and electronic devices over the last decades [1]. The high specific capacity and electrochemical specifications of nickel and cobalt transition metal chalcogenide compounds make them highly applicable for the LIBs. Among the cobalt and nickel cathode materials used in the $\mathrm{LIBs}, \mathrm{LiCoO}_{2}$ and $\mathrm{LiCo}_{\mathrm{x}} \mathrm{Ni}_{1-\mathrm{x}} \mathrm{O}_{2}(0 \leq \mathrm{x} \leq 1)$ are the most common compositions. From an environmental point of view, LIBs are composed of active ingredients, organic compounds and inorganic compounds, which must be properly managed. The economical aspects represent the LIBs as a recyclable resource for rare metals (e.g., nickel, cobalt and lithium). To support the environment and economy, some governments have restricted landfill disposal and mandated the collecting and recycling of used rechargeable batteries. To manage these 
wastes efficiently, several companies invented unique recycling and recovery systems [2]. Despite limitations on facilities and procedures, recycling the spent LIBs is of great importance with respect to retrieving high-value and energy-intensive cathode materials. Pyrometallurgical and hydrometallurgical methods are considered as the main recycling approaches while direct physical procedures are also practiced effectively to recover batteries' valuable materials in a mixture form. Hydrometallurgical methods mainly include the preparation of pregnant acid leached solution (PLS) using inorganic acids (e.g., $\mathrm{HNO}_{3}$, $\mathrm{H}_{2} \mathrm{SO}_{4}$ and $\mathrm{HCl}$ ) followed by selective down-stream processes such as solvent extraction, ion exchange, electrochemical and precipitation [3-11]. The extraction of metals from the PLS is not technically straightforward regarding the variety of species, and thus the presence and role of ligand(s) with a proper binding specification to the central metal atoms is critical [12-19]. Nowadays, more efficient recycling and leaching approaches are rapidly developing [20-22]. However, the main focus of this research is a rapid acquisition of leaching solution from cathode materials containing the main metals intended for the selective production of their sulfide phase.

Nanostructural materials have attracted favorable attention in many advanced applications (e.g., drug delivery, chemical sensors, catalysts and energy storage) because of their compositional and structural features, including a high specific surface area, permeable shell structures and a low mass density. Crystallinity, size and morphology are also some of the critical factors affecting the nanoparticles' applicability [23-25]. The importance of nanostructured materials is related to improving the electrochemical properties of practical applications (e.g., LIBs) by charge exchange and transfer [26]. Metal sulfide nanostructures are preferred in LIBs over metal oxides because of the lower electronegativity of elemental sulfur. As the electrode materials, nanostructure nickel and cobalt sulfides (e.g., CoS, $\mathrm{CoS}_{2}, \mathrm{Co}_{3} \mathrm{~S}_{4}, \mathrm{Co}_{9} \mathrm{~S}_{8}, \mathrm{NiS}, \mathrm{NiS}_{2}, \mathrm{Ni}_{3} \mathrm{~S}_{4}, \mathrm{Ni}_{3} \mathrm{~S}_{2}, \mathrm{NiCo}_{2} \mathrm{~S}_{4}, \mathrm{CoNi}_{2} \mathrm{~S}_{4}$ and $\mathrm{Ni}_{1.5} \mathrm{Co}_{1.5} \mathrm{~S}_{4}$ ) promote effective redox reactions in electrochemical energy storage devices (e.g., LIBs) [27-29]. Several methods have been applied to synthesize nickel and cobalt sulfide nanostructures using a dedicated source for nickel and cobalt (e.g., $\mathrm{NiCl}_{2}$ and $\left.\mathrm{Co}\left(\mathrm{No}_{3}\right)_{2}\right)$ and organosulfur (e.g., $\mathrm{CH}_{4} \mathrm{~N}_{2} \mathrm{~S}$ ) [30-32]. Nickel-sulfide (NiS) nanoparticles can be used in a wide range of applications within the new generation of batteries and supercapacitors, microelectronics, water-splitting, hydrodesulfurization, light-emitting diodes, high redox activity and high electrical conductivity. These applications of NiS nanoparticles are related to their valuable electronic and unique paramagnetic-antiferromagnetic transition and metal insulator properties, the low-cost counter electrode material of the solar cells, as well as their vast availability and low-cost [33-37]. Additionally, in the case of lithium battery anodes, other properties such as the carbon-sulfur bonds, improved characteristics of conductivity, volume-variation and active sites of the composites are very crucial [38].

The extraction of nanostructured metal sulfides from acid leached LIBs is a challenging task, since their PLS contains various metal ions (e.g., Ni, Co, $\mathrm{Li}$ and $\mathrm{Mn}$ ). In this case, the sulfur-containing ligand's role and the possible chemical interactions between different components of the PLS are the key points. Recently, leaching the cathode of disposable LIBs was introduced as an efficient method in view of the economic and environmental conditions for extracting valuable resources [39-42]. The production of high value-added materials like nanowire anodes [43] and nickel nanoparticles [44] from these sources provides a greater chance for the economic development of their recycling. However, the recycling of individual elements, especially nickel, is rarely explored in the literature. Nickel metal or nickel oxide nanoparticles have been successfully produced from leaching solutions of waste LIBs [45]. But the direct synthesis of crystalline NiS constitutes a new horizon for the recycling of precious metals from waste LIB sources, which is addressed in this research.

Alkali metal xanthate salts with the general formula of $\mathrm{ROCS}_{2}^{-} \mathrm{M}^{+}(\mathrm{R}=$ alkyl, $\mathrm{M}$ : $\mathrm{Na}, \mathrm{K}$ ) are organosulfur surfactants routinely used in mineral floatation and heavy metal removal from industry effluents. The xanthates are unstable and rapidly decompose under acidic conditions in contrast to neutral-alkaline conditions. Xanthates' solubility product 
constant $\left(\mathrm{K}_{\mathrm{sp}}\right)$ is an essential physicochemical parameter affecting the selective extraction of metals in hydrometallurgical methods. Different factors influence the $\mathrm{K}_{\mathrm{sp}}$ including solution $\mathrm{pH}$, available anions, cations and organics. In this regard, various chemical reactions including metal ion hydrolysis, metal hydroxide precipitation and the formation of soluble metal xanthate complexes may occur [46,47]. A low decomposition temperature $\left(\sim 20{ }^{\circ} \mathrm{C}\right)$ and high solubility lead xanthates to be suitable ligands for synthesizing various metal sulfide nanomaterials [31]. While having no influence on manganese and lithium, xanthate ligands' chemical reaction with nickel and cobalt results in the precipitation and formation of nickel and cobalt xanthates in acid leached LIBs [48]. Further thermal treatments of the formed nickel and cobalt xanthate decompose the organic part of the metal's xanthate composition, and the nano-sulfur metal can remain.

The present study aims to fabricate nanostructure nickel sulfides from spent LIBs. In this regard, two environmentally harmful heavy metals such as nickel and cobalt are recovered and transformed into usable materials. The novelty of the current study is to synthesize NiS nanoparticles through a hydrometallurgical process combined with a thermal treatment using a xanthate ligand. To the best of our knowledge, this paper is the first novel work to address the high potential selectivity of xanthates as ligands to recover metals during hydrometallurgical procedures.

\section{Materials and Methods}

\subsection{Materials and Reagents}

In this work, cathode materials (CMs) were collected from spent LIBs (Samsung galaxy core prime battery, cellphone battery). The chemical analysis of the $\mathrm{CM}$ presents a chemical combination of the battery containing $19.9 \% \mathrm{Co}, 27.7 \% \mathrm{Mn}, 2.6 \% \mathrm{Ni}, 4.6 \% \mathrm{Li}$ and $45.2 \% \mathrm{C}$ (as graphite). The other chemical reagents used in this study are sodium chloride $(\mathrm{NaCl})$, sulfuric acid $\left(\mathrm{H}_{2} \mathrm{SO}_{4}\right)$ as the leaching agent, potassium amyl xanthate $(99.5 \%$, $\left.\mathrm{CH}_{3}\left(\mathrm{CH}_{2}\right)_{4} \mathrm{OCS}_{2} \mathrm{~K}, \mathrm{PAX}\right)$ for the complexation of the PLS and ammonium hydroxide solution $\left(\mathrm{NH}_{4} \mathrm{OH}, 25-30 \%\right)$ for the washing process. All chemicals were purchased from the local suppliers (Kerman, Iran) with analytical grades.

\subsection{Characterization Methods}

The mineralogical identification of generated nanoparticles was studied with X-ray diffraction (XRD, X'pert-MPD Philips equipped with a detector using $\mathrm{Co}-\mathrm{K} \alpha$ radiation, Westborough, MA, USA). The particle size distribution and morphology of the nanoparticles were analyzed through transmission electron microscopy (TEM; Philips CM20, Hamburg, Germany) and scanning electron microscopy (SEM, Tescan Vega-II, TESCAN, Brno, Czech Republic), respectively. Furthermore, the elemental distributions of the nanopowders were characterized by a multipoint energy-dispersive X-ray spectrometer (EDS, Inca 300, Oxford Instruments, Oxford, UK). A Fourier-transform infrared (FT-IR) spectrometer (Bruker Tensor 27 instrument with RT-DLATGS detector, Berlin, Germany) was used to identify the functional groups in the final product in the wave range of $400-4000 \mathrm{~cm}^{-1}$. The $\mathrm{pH}$ of the PLS was continuously monitored by a pH-meter ( $827 \mathrm{pH}$ Metrohm, Herisau, Switzerland). Additionally, inductively coupled plasma optical emission spectrometry (ICP-OES, Perkin Elmer 7100 DV, PerkinElmer, Waltham, MA, USA) was used to exactly determine the elemental composition of the PLS and final product. TG-DTA (TG 209 F3 Tarsus ${ }^{\circledR}$, NETZSCH, Selb, Germany) was employed to determine the mechanism of decomposition of the nickel xanthate complex into the final NiS nanopowder.

\subsection{Preparation of Spent Batteries}

The LIBs were initially soaked into $1 \mathrm{M} \mathrm{NaCl}$ salt solution for eight hours followed by a drying process that lasted for $12 \mathrm{~h}$ at $60^{\circ} \mathrm{C}$. The cathode part of the LIBs was thereafter manually disassembled and sliced into $50 \mathrm{~mm} \times 50 \mathrm{~mm}$ parts. Furthermore, muffle furnace (KLS-M, Tuttlingen, Germany) preheating ( $300{ }^{\circ} \mathrm{C}$ for $30 \mathrm{~min}$ ) was applied to decompose the binder and other organic materials while simultaneously cathode materials 
were separated from the aluminum foil. Under this condition, cathode recovery from graphite was accomplished freely.

\subsection{Leaching Process}

Acidic leaching experiments (at $2 \mathrm{M} \mathrm{H}_{2} \mathrm{SO}_{4}$ ) were performed within a $1 \mathrm{~L}$ stirred tank reactor (STR) at $85^{\circ} \mathrm{C}, 700 \mathrm{rpm}$ and $20 \%(w / v)$ pulp density for $120 \mathrm{~min}$. Through a direct optimization process, $2 \%(v / v)$ oxygenated water $\left(\mathrm{H}_{2} \mathrm{O}_{2}\right)$ resulted in the highest recovery of nickel and cobalt (above $90 \%$ ) due to its high reducing power in converting $\mathrm{Co}^{3+}$ to $\mathrm{Co}^{2+}$ and significantly increasing its dissolution from the recalcitrant crystalline structure of $\mathrm{LiCoO}_{2}$ [49]. Table 1 presents the elemental compositions of the PLS and the filtered composition obtained using the (ICP-OES) analysis.

\subsection{Fabrication of Nanoparticles}

Figure 1 shows a top-down and stepwise operational diagram of the synthesis of NiS nanoparticles. The prepared PLS underwent complexation using potassium amyl xanthate $(1000 \mathrm{ppm})$ to obtain the coprecipitated nickel and cobalt xanthate residue. The filtered-precipitated residue was then washed up with ammonia solution $\left(2 \mathrm{M} \mathrm{NH}_{4} \mathrm{OH}\right)$ in order to separate the precipitated $\mathrm{Ni}$ from $\mathrm{Co}$ in the form of nickel ammonia sulfate. While nickel xanthate has a lower solubility $\left(\mathrm{K}_{\mathrm{sp}}\right)$ over cobalt xanthate, manganese and lithium ions do not react with the xanthate ligands and remain as sulfate phases [50,51]. To again form a nickel xanthate complex, $1000 \mathrm{ppm}$ PAX was added into the nickel-ammonia sulfate complex to precipitate a black-green residue. The cobalt xanthate (from the initial stage) and nickel xanthate (from the secondary stage) residues were filtered and subsequently washed with distilled water and ethanol and finally dried at $44^{\circ} \mathrm{C}$ before thermal treatment in a muffle furnace $\left(220^{\circ} \mathrm{C}, 1 \mathrm{~h}\right)$ for the fabrication of overall nanostructure nickel and cobalt sulfides. It is worth noting that in this research work the main emphasis was on recycling nickel as NiS nanoparticles in particular. Therefore, the production of other existing metal ions such as cobalt, manganese and lithium is under investigation and will be the subject of presentation in future works.

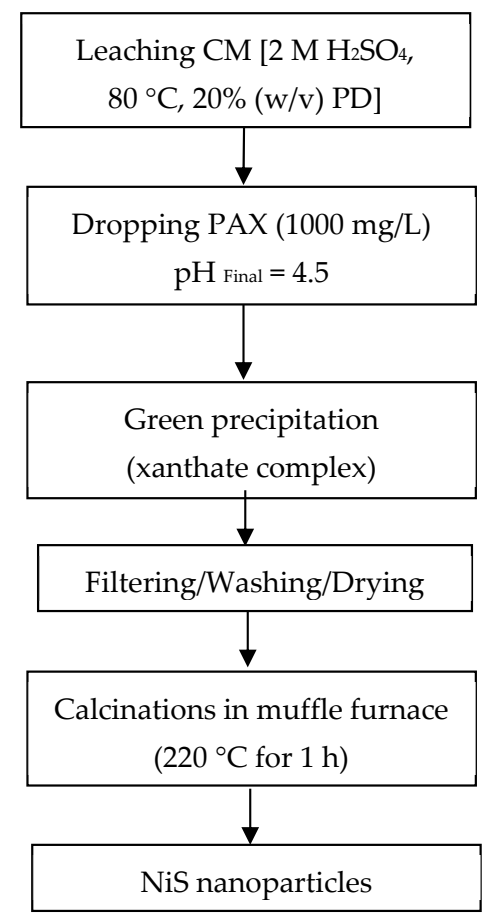

Figure 1. A demonstration of an experimental flow diagram for fabricating nanoparticles from the spent LIBs. 
Table 1. Elemental compositions of prepared and filtered PLS.

\begin{tabular}{ccccc}
\hline Component & Co & Mn & Ni & Li \\
\hline PLS (mg/L) & 3186.03 & 4155 & 443.1 & 793.7 \\
Feed CM (mg/L) & 199,127 & 27.7 & 26,105 & 46,690 \\
\hline
\end{tabular}

\section{Results and Discussions}

\subsection{X-Ray Powder Diffraction (XRD)}

The XRD patterns for the as-synthesized NiS are shown in Figure 2. The characteristic diffraction peaks completely match the hexagonal structure of the NiS phase (Crystallography Open Database (COD) code: 1010435 ) with lattice parameters of a $=3.4 \mathrm{~nm}$, $\mathrm{b}=3.4 \mathrm{~nm}$ and $\mathrm{c}=5.3 \mathrm{~nm}$ (space group P 63/m m c, \#194). As shown in Table 2, the mean crystalline size was estimated to be approximately $23.45 \mathrm{~nm}$ according to the Scherrer equation: $\mathrm{D}=(K \lambda) /(\beta \cos \theta)[52,53]$, where $K$ is the grain shape factor $(K=0.98), \lambda$ is the incident $X$-ray wavelength $(0.15418 \AA), \theta$ is the diffraction angle in degrees and $\beta$ is the full width at half-maximum intensity (FWHM) in radians $[19,52,54]$.

Table 2. Representative crystallographic X-ray diffraction data for NiS nanoparticles.

\begin{tabular}{|c|c|c|c|c|c|c|}
\hline hkl & Pos. $\left({ }^{\circ} 2 \mathrm{Th}.\right)$ & d-spacing $(\AA)$ & Crystallite Size (Å) & Microstrain (\%) & $\begin{array}{c}\text { Crystallite Size } \\
\text { Only (ঐ) }\end{array}$ & $\begin{array}{c}\text { Microstrain } \\
\text { Only (\%) }\end{array}$ \\
\hline 100 & 30.4666 & 2.93168 & 261.8913 & 0.522286 & 157.3711 & 0.931453 \\
\hline 101 & 34.9458 & 2.56549 & 349.4471 & 0.357726 & 205.2646 & 0.624922 \\
\hline 102 & 46.1364 & 1.96592 & 362.6012 & 0.264356 & 212.9156 & 0.461666 \\
\hline 110 & 53.7784 & 1.70320 & 284.0213 & 0.280356 & 170.4897 & 0.499501 \\
\hline 103 & 61.0836 & 1.51584 & 390.6485 & 0.190465 & 228.5735 & 0.331587 \\
\hline 201 & 65.4320 & 1.42523 & 303.3146 & 0.221017 & 181.4979 & 0.392629 \\
\hline 004 & 71.0005 & 1.32649 & 252.9233 & 0.240170 & 153.4484 & 0.432225 \\
\hline 202 & 73.2689 & 1.29092 & 320.6339 & 0.190644 & 191.1957 & 0.33759 \\
\hline \multicolumn{3}{|c|}{ Average crystallite size $(\AA)$} & 315.68515 & & 187.5945625 & \\
\hline
\end{tabular}

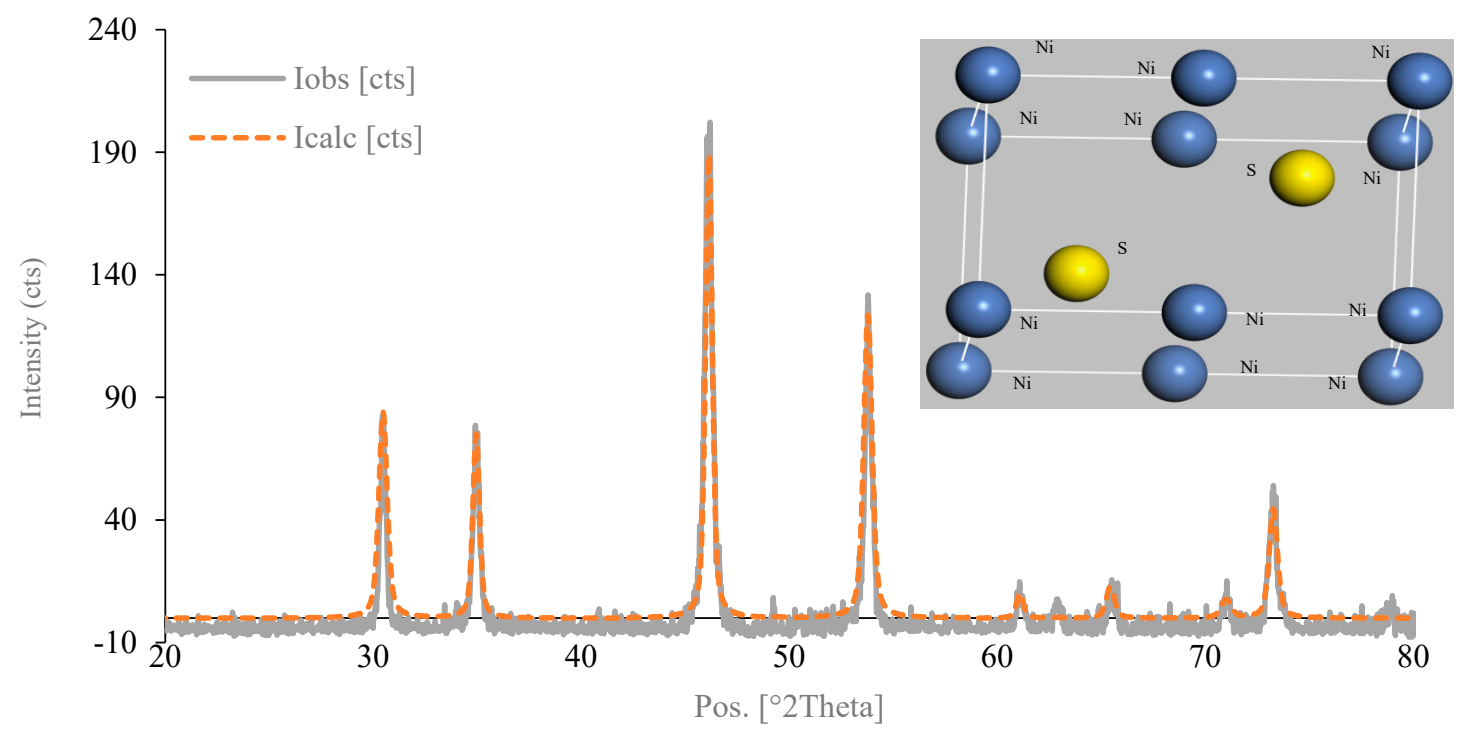

Figure 2. XRD patterns and crystallographic depiction of hexagonal nickel sulfide (NiS) nanoparticles.

The Rietveld method may calculate the crystallite size and/or microstrain of the as-synthesized NiS based on the change of the profile parameters when compared to a standard NiS crystal (Reference code: 96-101-0436). It is worth mentioning that the profile parameters depend on the instrumental settings used for the data collection and on the 
profile function used for the refinement (Size/strain analysis, help of software Malvern Panalytical's HighScorePlus, UK).

\subsection{Thermogravimetry \& Differential Thermal Analysis (TGA-DTA)}

Figure 3 demonstrates the TGA-DTA analysis of the nickel-xanthate complex. The first derivative of the curve manifested the occurrence of decomposition in a single step. The experimental mass lost at $220^{\circ} \mathrm{C}$ was slightly lower $(72.88 \%)$ than the lost amount that was calculated $(76.36 \%)$ for the NiS formation from the complex. The XRD indicated that the NiS was the only phase formed (Figure 2). However, the small discrepancy between the measured and calculated weight that was lost could be partially explained by the presence of water adsorption, sulfate and possibly other xanthate decomposition products on the surface of the NiS nanocrystals.

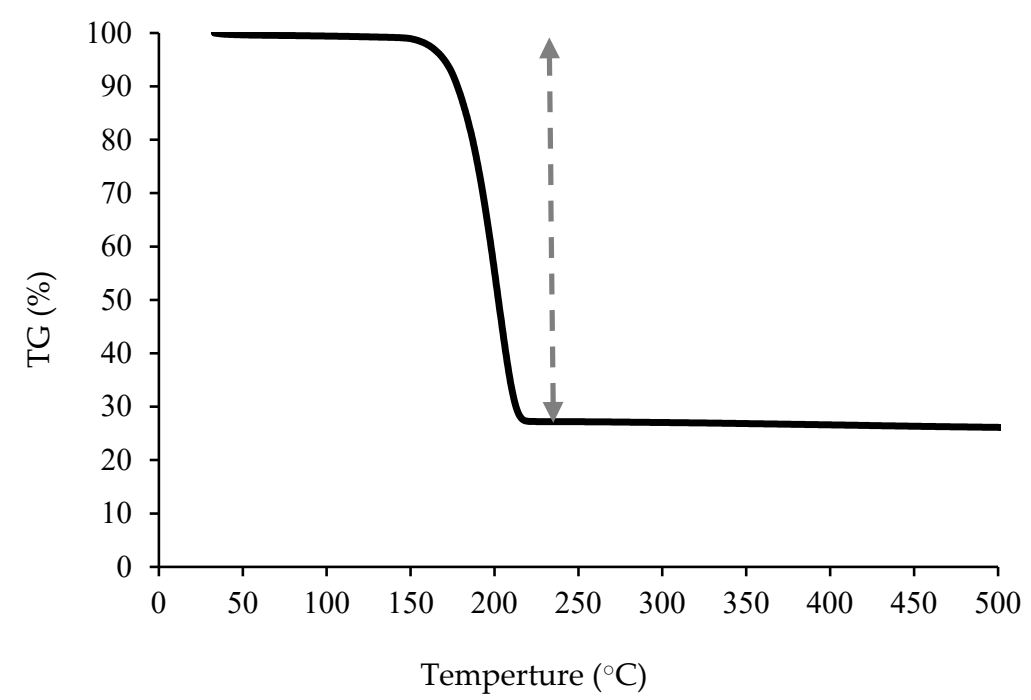

Figure 3. TGA-DTA analysis of the thermal decomposition of the $\mathrm{Ni}\left(\mathrm{S}_{2} \mathrm{CO}\left(\mathrm{CH}_{2}\right)_{4} \mathrm{CH}_{3}\right)_{2}$ complex into pure NiS nanopowder.

The straightforward diagram of the thermogravimetry (TG) analysis was in fact implicitly indicative of the purity of the $\mathrm{Ni}\left(\mathrm{S}_{2} \mathrm{CO}\left(\mathrm{CH}_{2}\right)_{4} \mathrm{CH}_{3}\right)_{2}$ complex, whose thermal decomposition at $220^{\circ} \mathrm{C}$ resulted in the production of a pure and uniform NiS nanopowder. It is worth noting that the thermal analysis showed that a temperature of $220{ }^{\circ} \mathrm{C}$ was sufficient and suitable to completely convert the amylxanthate into the sulfide (Figure 3). Based on the TGA-DTA analysis, the reaction mechanism of metal sulfide formation from the nickel-xanthate complex pathway was proposed as presented in Figure 4.
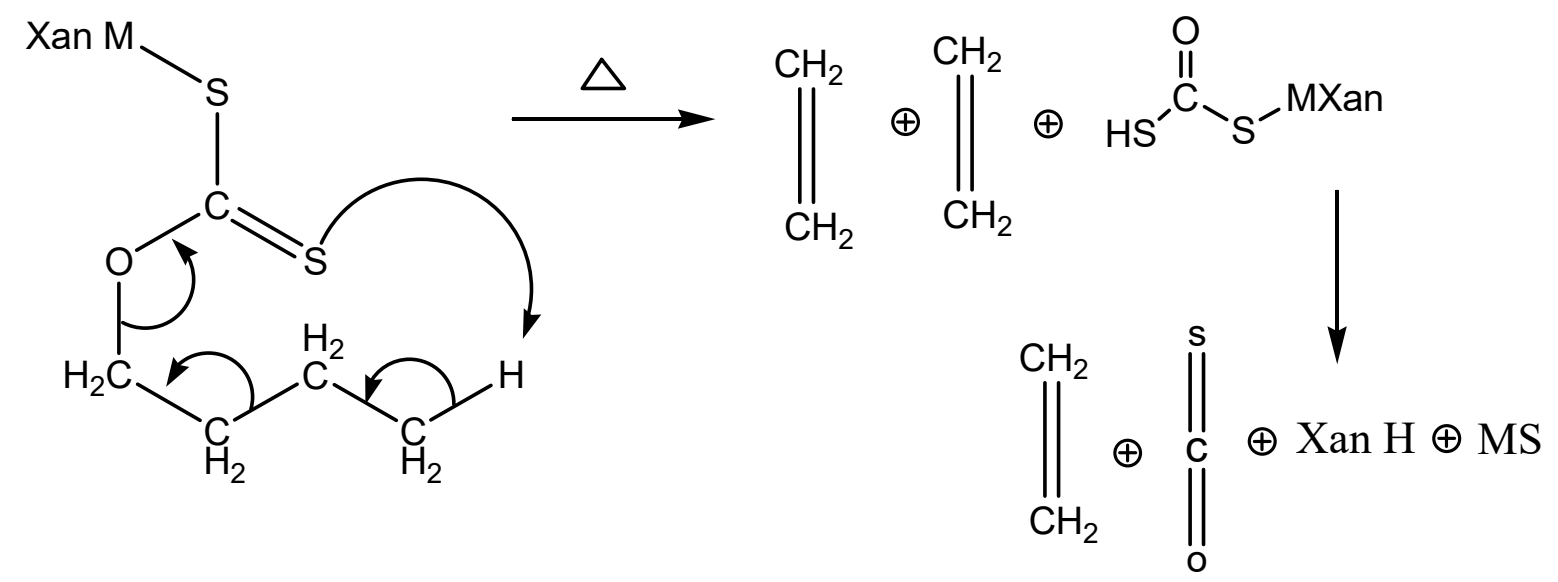

Figure 4. The suggested mechanism of the decomposition of the nickel xanthate complex into its derivatives through the Chugaev reaction. 
By adding the xanthate solution to the PLS in a dropwise manner, the following reaction actually occurred:

$$
\left.\mathrm{Ni}^{2+}+2 \mathrm{KS}_{2} \mathrm{CO}\left(\mathrm{CH}_{2}\right)_{4} \mathrm{CH}_{3}\right)_{2}(\mathrm{aq}) \rightarrow \mathrm{Ni}\left(\mathrm{S}_{2} \mathrm{CO}\left(\mathrm{CH}_{2}\right)_{4} \mathrm{CH}_{3}\right)_{2}(\mathrm{~s})+2 \mathrm{~K}^{+}
$$

It was reported that the thermal decomposition of the solid product followed the Chugaev reaction pathway to produce alkene $\left(\mathrm{C}_{2} \mathrm{H}_{4}\right)$, carbonyl sulfide (COS) and alkyl thiol (R-SH) as volatiles, and NiS as a pure solid product $[55,56]$.

\subsection{Fourier-Transform Infrared (FTIR) Spectroscopy}

The as-synthesized NiS was analyzed by the FTIR spectrum while considering the main absorption peaks at about 3434,1631, 1138 and $641 \mathrm{~cm}^{-1}$. The two absorption peaks of 3442 and $1631 \mathrm{~cm}^{-1}$ were attributed to the vibration of $\mathrm{OH}$ groups of $\mathrm{H}_{2} \mathrm{O}[19,52]$. The peak at $2351 \mathrm{~cm}^{-1}$ can be assigned to the $\mathrm{C}-\mathrm{O}$ bond originating from the adsorption of $\mathrm{CO}_{2}$ (from the atmosphere and/or the reaction product) [19,54]. The bands at $638 \mathrm{~cm}^{-1}$, $641 \mathrm{~cm}^{-1}$ and $964 \mathrm{~cm}^{-1}$ were related to the symmetrical and asymmetrical stretch of the $\mathrm{Ni}-\mathrm{S}$ band in NiS particles [57]. The bending vibration of the sulfonated group appeared at $1138 \mathrm{~cm}^{-1}$ (Figure 5). Furthermore, elemental analysis obtained by the ICP-OES method indicates a high purity $(98.94 \%)$ of the fabricated nanopowders (Table 3). Additionally, the FTIR analysis (Figure 5) implicitly indicates the high purity of the powder, since the presence of even very low amounts (below 1\%) of impurities in the powder can show certain peaks in this analysis.

\subsection{Scanning Electron Microscopy (SEM) Energy Dispersive X-Ray Spectrum (EDS)}

Figure 6a illustrates the SEM photomicrograph of NiS nanoparticles. The agglomerated form of the nanoparticles was due to the thermal decomposition. The morphology of the NiS was characterized by spherical-shaped particles with a uniform distribution.

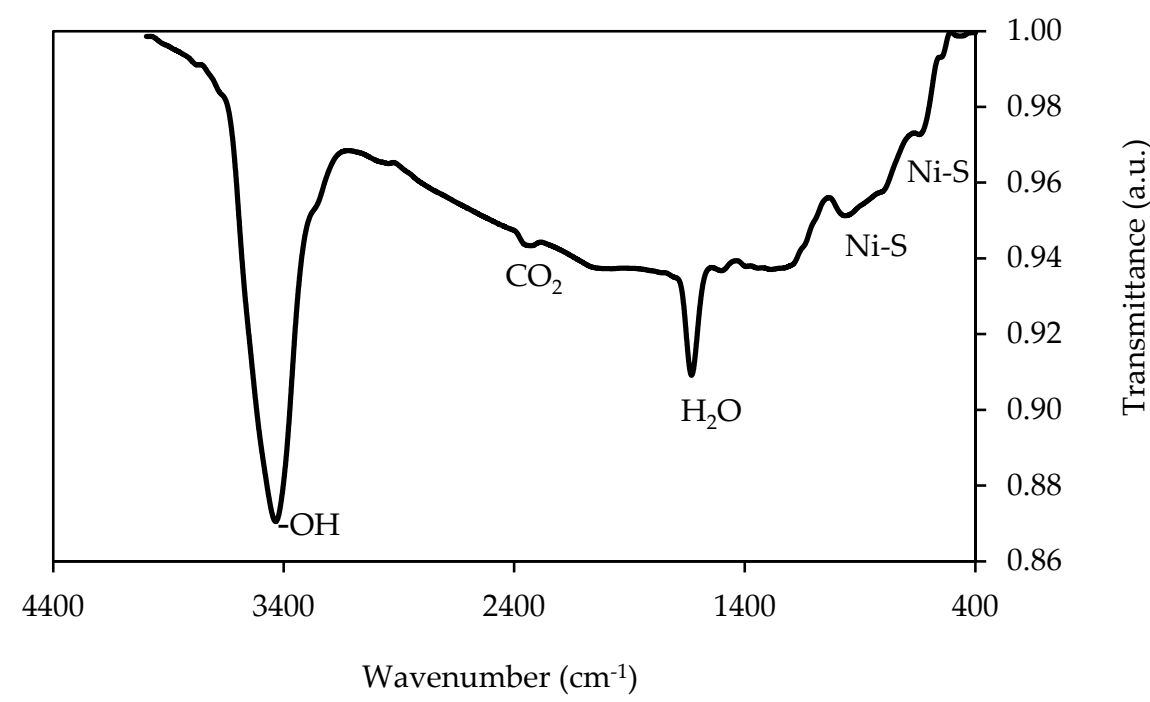

Figure 5. FTIR spectrum of the as-synthesized NiS nanoparticles.

The EDS reveals the purity of the powder, with only $\mathrm{Ni}$ and $\mathrm{S}$ elements at atomic percentages of 48.2 and 51.8, respectively (Figure 6b). The XRD, FTIR and EDS analyses also confirm the high purity of the nanoparticles (Figures 2, 5 and $6 \mathrm{~b}$ )

\subsection{Transmission Electron Microscopy (TEM)}

Figure 7 shows the TEM image of spherical NiS nanoparticles with an average diameter of $61 \pm 2 \mathrm{~nm}$. The particle size distribution (PSD) was evaluated based on 25 different images, counting about 250 particles (ImageJ 1.x software, the Laboratory for Optical and 
Computational Instrumentation (LOCI, University of Wisconsin, Madison, WI, USA)). The PSD showed a narrow size distribution range of 22 to $106 \mathrm{~nm}$ (average size of $61 \mathrm{~nm}$ ).

Table 3. ICP-OES and wet chemical analysis of the as-fabricated NiS nanoparticles.

\begin{tabular}{cc}
\hline Composition & Concentration of the Elements (\%) \\
\hline $\mathrm{Ni}$ & 63.98 \\
$\mathrm{~S}$ & 34.95 \\
$\mathrm{Co}$ & 0.32 \\
$\mathrm{Cu}$ & 0.21 \\
$\mathrm{Cd}$ & 0.11 \\
$\mathrm{Na}$ & 0.02 \\
$\mathrm{Li}$ & 0.12 \\
$\mathrm{Mn}$ & 0.11 \\
$\mathrm{Si}$ & 0.04 \\
$\mathrm{Cl}$ & 0.10 \\
$\mathrm{Al}$ & 0.03 \\
\hline
\end{tabular}
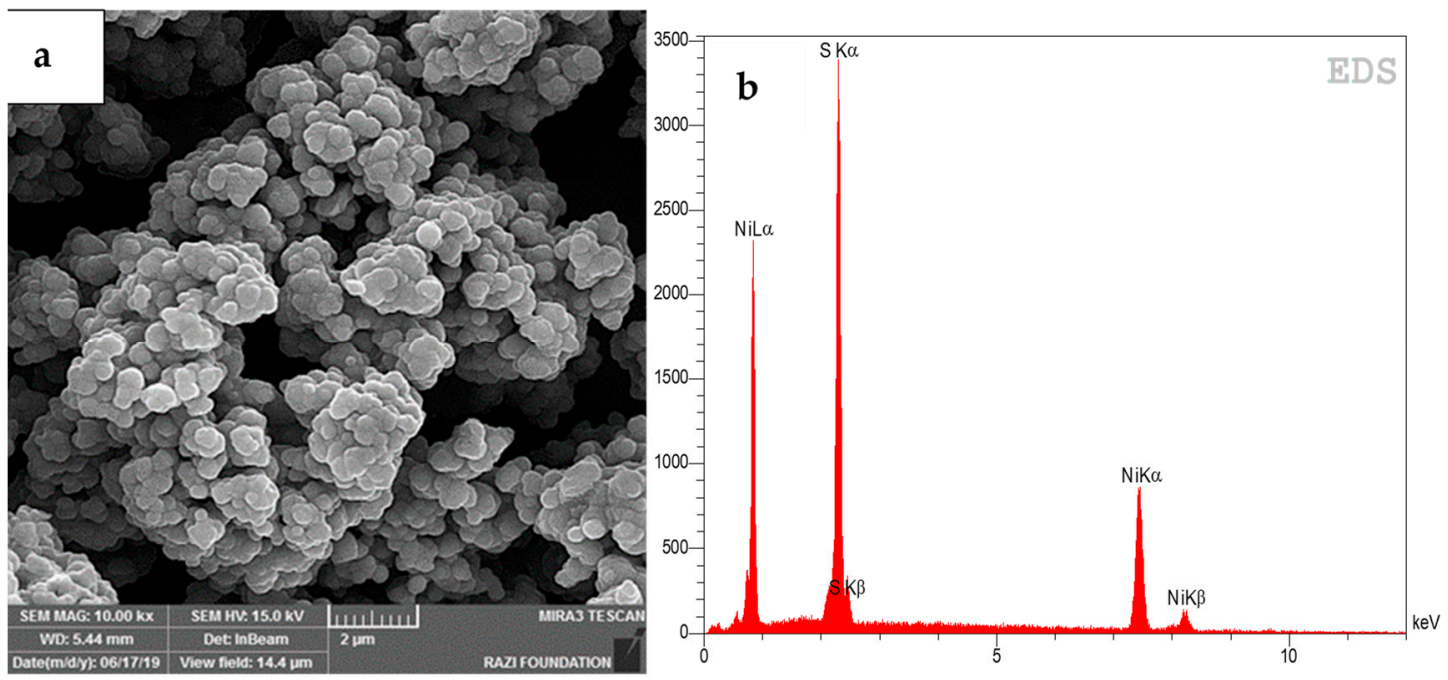

Figure 6. (a) SEM image and (b) EDS analysis from the as-prepared NiS nanoarchitecture.
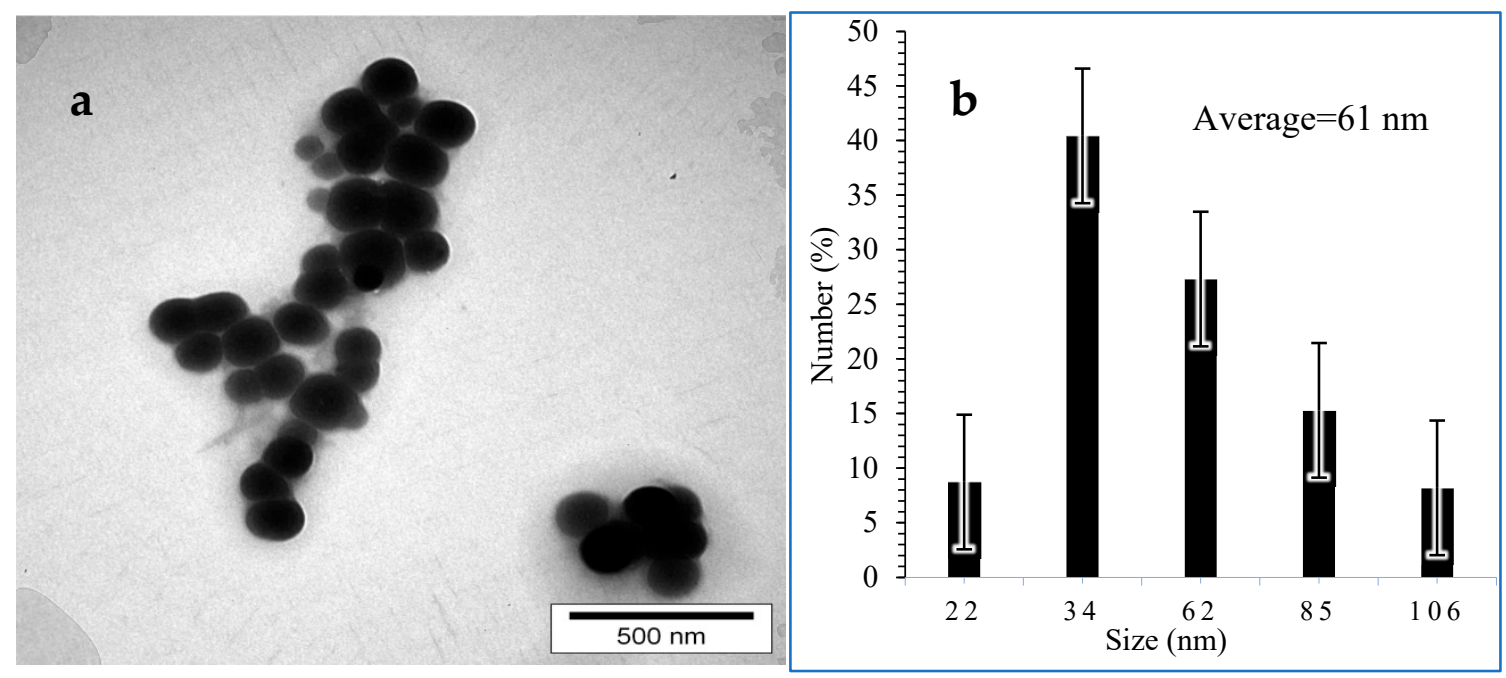

Figure 7. (a) TEM analysis and (b) the related PSD of the NiS nanopowder. 
As shown in Figure 7, the TEM analysis also constituted the other verification for the purity of the as-synthesized NiS, since the crystals were completely uniform without any other heterogeneous crystals. By comparing the results of the SEM (Figure 6a) and TEM (Figure 7a) images morphologically, one can observe that the SEM shows a nonspherical shape for the synthesized particles while the shape is relatively spherical when using the TEM. This is because the newly formed and somewhat incomplete particles, which are also characterized by XRD analysis, may change their morphology when heated for decomposition because of the phenomenon of sintering and agglomeration. Due to differences in the mechanisms of these two analyses, in the SEM analysis the as-synthesized particles are directly imaged after the furnace $\left(220^{\circ} \mathrm{C}\right)$. However, in the TEM analysis, which uses strong ultrasonication $(40 \mathrm{kHz})$ for $30 \mathrm{~min}$, particles are given a chance to completely differentiate and disperse. Thus, in terms of sintering, the morphology displayed in the SEM picture is somewhat different than that shown by the TEM, which is spherical and closer to the original particles.

\subsection{Photon Correlation Spectroscopy (PCS)}

By using the PCS particle size analysis, the size distribution of the NiS nanoparticles was also obtained (Figure 8). By comparing the TEM and PCS analyses it was revealed that the average particle sizes of the NiS nanoparticles were about 61 and 64 , respectively. The negligible difference in sizes can be related to the electrostatic forces between particles and, in the PCS analysis, to agglomeration.

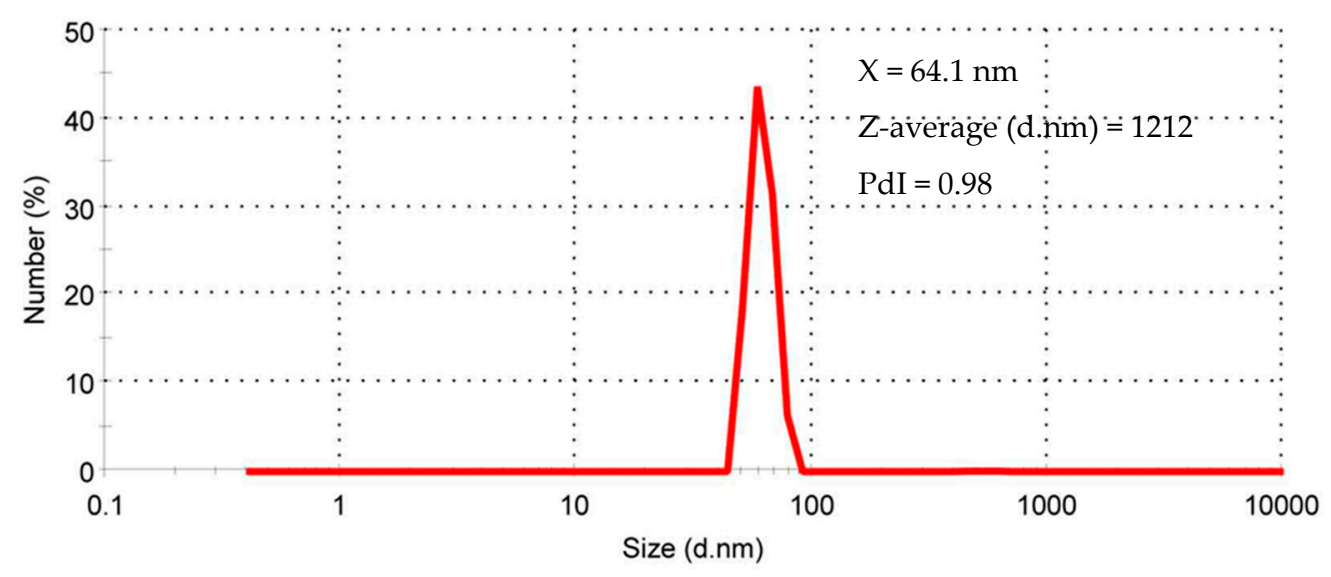

Figure 8. PSD of the as-fabricated NiS nanoparticles with the PCS analysis.

\section{Conclusions}

The main motivation of this research is to recycle NiS nanopowders from spent LIBs. This was obtained through a facilitated method with mild conditions (complexation at an ambient temperature and then thermal decomposition at $220^{\circ} \mathrm{C}$ for $1 \mathrm{~h}$ ). The mineralogical and particle size properties of the produced nanoparticles were respectively characterized by XRD and TEM as well as PCS analyses. Additionally, their elemental distributions and functional groups were assessed by the ICP-OES, EDS and FTIR methods, respectively. The characteristic analysis of the as-prepared NiS identified a mean particle size of $61 \pm 2 \mathrm{~nm}$ (by TEM) and $64 \mathrm{~nm}$ (through the PCS method) with high purities approved via XRD and EDS analyses. According to the obtained XRD data and the standard ones, they matched well with the hexagonal structure of the NiS phase. The results of the FTIR data disclosed that bands of 638,641 and $964 \mathrm{~cm}^{-1}$ were related to the stretch of the NiS band. These results were highly correlated with the data obtained by ICP-OES. The morphological analyses using SEM and TEM disclosed a discrepancy with respect to the differences in the mechanisms of these two techniques. SEM displayed a non-spherical shape for the synthesized nanoparticles while the shape given by the TEM was relatively spherical. We finally concluded that the results of the present research could be considered a new path for 
producing extremely valuable and pure nanomaterials from industrial e-wastes without requiring high costs and complex processes like solvent extraction.

Author Contributions: Conceptualization: E.D and A.B.V.; Methodology, Investigation, Writingoriginal draft: E.D. and A.B.V.; Validation, Formal analysis, Visualization, Writing-review \& editing: E.D, A.B.V. and A.H.: Writing-review \& editing, Supervision: T.N., A.S., E.D., A.B.V. and A.H. Data curation. B.K. All authors have read and agreed to the published version of the manuscript.

Funding: Funding for this research work was provided by the Iran National Science Foundation (INSF) under grant number of 98/S/8700.

Data Availability Statement: The data presented in this study is available on request from the corresponding authors. The data is not publicly available due to the confidentiality of the research work.

Acknowledgments: We are grateful to Shahid Bahonar University of Kerman and Graduate University of Advanced Technology for supporting this research study and providing all the facilities required for conducting the experimental works. Additionally, we would like to thank the anonymous reviewers for their insightful remarks, constructive comments and fruitful criticisms.

Conflicts of Interest: The authors declare that they have no conflict of interest.

\section{References}

1. Ciez, R.E.; Whitacre, J. Examining different recycling processes for lithium-ion batteries. Nat. Sustain. 2019, 2, 148-156. [CrossRef]

2. Wang, W.; Wu, Y. An overview of recycling and treatment of spent LiFePO4 batteries in China. Resour. Conserv. Recy. 2017, 127, 233-243. [CrossRef]

3. Chen, L.; Tang, X.; Zhang, Y.; Li, L.; Zeng, Z.; Zhang, Y. Process for the recovery of cobalt oxalate from spent lithium-ion batteries. Hydrometallurgy 2011, 108, 80-86. [CrossRef]

4. Kang, J.; Senanayake, G.; Sohn, J.; Shin, S.-M. Recovery of cobalt sulfate from spent lithium ion batteries by reductive leaching and solvent extraction with Cyanex 272. Hydrometallurgy 2010, 100, 168-171. [CrossRef]

5. Pranolo, Y.; Zhang, W.; Cheng, C. Recovery of metals from spent lithium-ion battery leach solutions with a mixed solvent extractant system. Hydrometallurgy 2010, 102, 37-42. [CrossRef]

6. Lupi, C.; Pasquali, M. Electrolytic nickel recovery from lithium-ion batteries. Miner. Eng. 2003, 16, 537-542. [CrossRef]

7. Pinegar, H.; Smith, Y.R. Recycling of end-of-life lithium ion batteries, Part I: Commercial processes. J. Sustain. Met. 2019, 5, 402-416. [CrossRef]

8. Flett, D.S. Cobalt-nickel separation in hydrometallurgy: A review. Chem. Sustain. Dev. 2004, 12, 81-91.

9. Armstrong, R.D.; Todd, M.; Atkinson, J.W.; Scott, K. Electroseparation of cobalt and nickel from a simulated wastewater. J. Appl. Electrochem. 1997, 27, 965-969. [CrossRef]

10. Castillo, S.; Ansart, F.; Laberty-Robert, C.; Portal, J. Advances in the recovering of spent lithium battery compounds. J. Power Source 2002, 112, 247-254. [CrossRef]

11. Miller, M.J.; Scheithauer, R.A. Method for Separation of Cobalt from Nickel. U.S. Patent 2,842,427, 8 July 1958.

12. Liu, P.; Xiao, L.; Chen, Y.; Tang, Y.; Wu, J.; Chen, H. Recovering valuable metals from LiNixCoyMn1-x-yO ${ }_{2}$ cathode materials of spent lithium ion batteries via a combination of reduction roasting and stepwise leaching. J. Alloys Compd. 2019, 783, 743-752. [CrossRef]

13. Chen, X.; Kang, D.; Cao, L.; Li, J.; Zhou, T.; Ma, H. Separation and recovery of valuable metals from spent lithium ion batteries: Simultaneous recovery of $\mathrm{Li}$ and Co in a single step. Sep. Purif. Technol. 2019, 210, 690-697. [CrossRef]

14. Fu, Y.; He, Y.; Qu, L.; Feng, Y.; Li, J.; Liu, J.; Zhang, G.; Xie, W. Enhancement in leaching process of lithium and cobalt from spent lithium-ion batteries using benzenesulfonic acid system. Waste Manag. 2019, 88, 191-199. [CrossRef] [PubMed]

15. Nayaka, G.P.; Zhang, Y.; Dong, P.; Wang, D.; Zhou, Z.; Duan, J.; Li, X.; Lin, Y.; Meng, Q.; Pai, K.V.; et al. An environmental friendly attempt to recycle the spent Li-ion battery cathode through organic acid leaching. J. Environ. Chem. Eng. 2019, 7, 102854. [CrossRef]

16. Shih, Y.-J.; Chien, S.-K.; Jhang, S.-R.; Lin, Y.-C. Chemical leaching, precipitation and solvent extraction for sequential separation of valuable metals in cathode material of spent lithium ion batteries. J. Taiwan Inst. Chem. E 2019, 100, 151-159. [CrossRef]

17. Wu, C.; Li, B.; Yuan, C.; Ni, S.; Li, L. Recycling valuable metals from spent lithium-ion batteries by ammonium sulfite-reduction ammonia leaching. Waste Manag. 2019, 93, 153-161. [CrossRef] [PubMed]

18. Gao, G.; Luo, X.; Lou, X.; Guo, Y.; Su, R.; Guan, J.; Li, Y.; Yuan, H.; Dai, J.; Jiao, Z. Efficient sulfuric acid-Vitamin C leaching system: Towards enhanced extraction of cobalt from spent lithium-ion batteries. J. Mater. Cycles Waste 2019, 21, 942-949. [CrossRef]

19. Vakylabad, A.B.; Schaffie, M.; Naseri, A.; Ranjbar, M.; Manafi, Z. A procedure for processing of pregnant leach solution (PLS) produced from a chalcopyrite-ore bio-heap: CuO Nano-powder fabrication. Hydrometallurgy 2016, 163, 24-32. [CrossRef]

20. Bai, Y.; Blake Hawley, W.; Jafta, C.J.; Muralidharan, N.; Polzin, B.J.; Belharouak, I. Sustainable recycling of cathode scraps via Cyrene-based separation. Sustain. Mater. Technol. 2020, 25, e00202. [CrossRef] 
21. Bai, Y.; Muralidharan, N.; Li, J.; Essehli, R.; Belharouak, I. Sustainable direct recycling of lithium-ion batteries via solvent recovery of electrode materials. ChemSusChem 2020, 13, 5664-5670. [CrossRef]

22. Bai, Y.; Muralidharan, N.; Sun, Y.-K.; Passerini, S.; Stanley Whittingham, M.; Belharouak, I. Energy and environmental aspects in recycling lithium-ion batteries: Concept of Battery Identity Global Passport. Mater. Today 2020, 41, 304-315. [CrossRef]

23. Walton, R.I. Subcritical solvothermal synthesis of condensed inorganic materials. Chem. Soc. Rev. 2002, 31, 230-238. [CrossRef] [PubMed]

24. Man, R.W.; Brown, A.R.; Wolf, M.O. Mechanism of Formation of Palladium Nanoparticles: Lewis Base Assisted, Low-Temperature Preparation of Monodisperse Nanoparticles. Angew. Chem. Int. Ed. 2012, 51, 11350-11353. [CrossRef]

25. Yu, H.; Gibbons, P.C.; Kelton, K.F.; Buhro, W.E. Heterogeneous seeded growth: A potentially general synthesis of monodisperse metallic nanoparticles. J. Am. Chem. Soc. 2001, 123, 9198-9199. [CrossRef] [PubMed]

26. Chen, Z.; Wan, Z.; Yang, T.; Zhao, M.; Lv, X.; Wang, H.; Ren, X.; Mei, X. Preparation of Nickel Cobalt Sulfide Hollow Nanocolloids with Enhanced Electrochemical Property for Supercapacitors Application. Sci. Rep. UK 2016, 6, 25151. [CrossRef]

27. RECHARGE-The-Batteries-Report-2018-April-18.pdf. Available online: https://www.storelio.com/files (accessed on 14 January 2021).

28. Chen, X.; Liu, Q.; Bai, T.; Wang, W.; He, F.; Ye, M. Nickel and Cobalt Sulfide-Based Nanostructured Materials for Electrochemical Energy Storage Devices. Chem. Eng. J. 2020, 409, 127237. [CrossRef]

29. Koohestani, B.; Khodadadi Darban, A.; Mokhtari, P.; Darezereshki, E.; Yilmaz, E.; Yilmaz, E. Influence of Hydrofluoric Acid Leaching and Roasting on Mineralogical Phase Transformation of Pyrite in Sulfidic Mine Tailings. Minerals 2020, 10, 513. [CrossRef]

30. Akram, R.; Khan, M.D.; Zequine, C.; Zhao, C.; Gupta, R.K.; Akhtar, M.; Akhtar, J.; Malik, M.A.; Revaprasadu, N.; Bhatti, M.H. Cobalt sulfide nanoparticles: Synthesis, water splitting and supercapacitance studies. Mat. Sci. Semicon. Proc. 2020, 109, 104925. [CrossRef]

31. Buchmaier, C.; Glänzer, M.; Torvisco, A.; Poelt, P.; Wewerka, K.; Kunert, B.; Gatterer, K.; Trimmel, G.; Rath, T. Nickel sulfide thin films and nanocrystals synthesized from nickel xanthate precursors. J. Mater. Sci. 2017, 52, 10898-10914. [CrossRef]

32. Guan, B.; Li, Y.; Yin, B.; Liu, K.; Wang, D.; Zhang, H.; Cheng, C. Synthesis of hierarchical NiS microflowers for high performance asymmetric supercapacitor. Chem. Eng. J. 2017, 308, 1165-1173. [CrossRef]

33. Edison, T.N.J.I.; Atchudan, R.; Lee, Y.-R. Binder-free electro-synthesis of highly ordered nickel oxide nanoparticles and its electrochemical performance. Electrochim. Acta 2018, 283, 1609-1617. [CrossRef]

34. Sathiyaraj, E.; Thirumaran, S.; Ciattini, S.; Selvanayagm, S. Synthesis and characterization of Ni (II) complexes with functionalized dithiocarbamates: New single source precursors for nickel sulfide and nickel-iron sulfide nanoparticles. Inorg. Chim. Acta 2019, 498, 119162. [CrossRef]

35. Ravindhranath, K.; Ramamoorty, M. Nickel Based Nano Particles as Adsorbents in Water Purification Methods-A Review. Orient. J. Chem. 2017, 33, 1603. [CrossRef]

36. Cao, L.; Tang, G.; Mei, J.; Liu, H. Construct hierarchical electrode with NixCo3-xS4 nanosheet coated on NiCo2O4 nanowire arrays grown on carbon fiber paper for high-performance asymmetric supercapacitors. J. Power Source 2017, 359, 262-269. [CrossRef]

37. Mani, A.D.; Deepa, M.; Xanthopoulos, N.; Subrahmanyam, C. Novel one pot stoichiometric synthesis of nickel sulfide nanomaterials as counter electrodes for QDSSCs. Mater. Chem. Phys. 2014, 148, 395-402. [CrossRef]

38. Ren, H.; Wang, J.; Cao, Y.; Luo, W.; Sun, Y. Nickel sulfide nanoparticle anchored reduced graphene oxide with improved lithium storage properties. Mater. Res. Bull. 2021, 133, 111047. [CrossRef]

39. Chen, M.; Wang, R.; Qi, Y.; Han, Y.; Wang, R.; Fu, J.; Meng, F.; Yi, X.; Huang, J.; Shu, J. Cobalt and lithium leaching from waste lithium ion batteries by glycine. J. Power Source 2021, 482, 228942. [CrossRef]

40. Liu, K.; Yang, S.; Lai, F.; Wang, H.; Huang, Y.; Zheng, F.; Wang, S.; Zhang, X.; Li, Q. Innovative Electrochemical Strategy to Recovery of Cathode and Efficient Lithium Leaching from Spent Lithium-Ion Batteries. ACS Appl. Energy Mater. 2020, 3 , 4767-4776. [CrossRef]

41. Fan, E.; Yang, J.; Huang, Y.; Lin, J.; Arshad, F.; Wu, F.; Li, L.; Chen, R. Leaching Mechanisms of Recycling Valuable Metals from Spent Lithium-Ion Batteries by a Malonic Acid-Based Leaching System. ACS Appl. Energy Mater. 2020, 3, 8532-8542. [CrossRef]

42. Refly, S.; Floweri, O.; Mayangsari, T.R.; Sumboja, A.; Santosa, S.P.; Ogi, T.; Iskandar, F. Regeneration of $\mathrm{LiNi}_{1} / 3 \mathrm{Co}_{1} / 3 \mathrm{Mn}_{1} / 3 \mathrm{O}_{2}$ Cathode Active Materials from End-of-Life Lithium-Ion Batteries through Ascorbic Acid Leaching and Oxalic Acid Coprecipitation Processes. ACS Sustain. Chem. Eng. 2020, 8, 16104-16114. [CrossRef]

43. Schiavi, P.G.; Farina, L.; Zanoni, R.; Altimari, P.; Cojocariu, I.; Rubino, A.; Navarra, M.A.; Panero, S.; Pagnanelli, S. Electrochemical synthesis of nanowire anodes from spent lithium ion batteries. Electrochim. Acta 2019, 319, 481-489. [CrossRef]

44. Shin, S.-M.; Lee, D.-W.; Wang, J.-P. Fabrication of nickel nanosized powder from linio2 from spent lithium-ion battery. Metals 2018, 8, 79. [CrossRef]

45. Ebin, B. Simple Preparation of Ni and NiO Nanoparticles Using Raffinate Solution Originated from Spent NiMH Battery Recycling. J. Inorg. Organomet. Polym. Mater. 2018, 28, 2554-2563. [CrossRef]

46. Tipman, N.R. Reactions of Potassium Ethyl Xanthate in Aqueous Solution; University of British Columbia: Vancouver, BC, Canada, 1970.

47. Zhang, Y.-H.; Wu, L.-M.; Huang, P.-P.; Shen, Q.; Sun, Z.-X. Determination and application of the solubility product of metal xanthate in mineral flotation and heavy metal removal in wastewater treatment. Miner. Eng. 2018, 127, 67-73. [CrossRef] 
48. Yang, Y.; Liu, F.; Song, S.; Tang, H.; Ding, S.; Sun, W.; Lei, S.; Xu, S. Recovering valuable metals from the leaching liquor of blended cathode material of spent lithium-ion battery. J. Environ. Chem. Eng. 2020, 8, 104358. [CrossRef]

49. Aaltonen, M.; Peng, C.; Wilson, B.P.; Lundström, M. Leaching of metals from spent lithium-ion batteries. Recycling 2017, 2, 20. [CrossRef]

50. Sasaki, Y. Extraction-Spectrophotometric determination of manganese (II) with xanthates. Anal. Chim. Acta 1982, 138, 419-424. [CrossRef]

51. Pilipenko, A.; Ul'ko, N. Analytical Prverties of Xanthates (III). Zh. Analit. Khim 1955, 10, 299-304.

52. Darezereshki, E.; Bakhtiari, F.; Alizadeh, M.; Vakylabad, B.A.; Ranjbar, M. Direct thermal decomposition synthesis and characterization of hematite $\left(\alpha-\mathrm{Fe}_{2} \mathrm{O}_{3}\right)$ nanoparticles. Mat. Sci. Semicon. Proc. 2012, 15, 91-97. [CrossRef]

53. Darezereshki, E.; Khodadadi Darban, A.; Abdollahy, M.; Jamshidi-Zanjani, A.; Vakylabad, B.A.; Mohammadnejad, S. The leachability study of iron-oxides from mine tailings in a hybrid of sulfate-chloride lixiviant. J. Environ. Chem. Eng. 2018, 6, 5167-5176. [CrossRef]

54. Darezereshki, E.; Ranjbar, M.; Bakhtiari, F. One-step synthesis of maghemite ( $\gamma$-Fe2O3) nano-particles by wet chemical method. J. Alloys Compd. 2010, 502, 257-260. [CrossRef]

55. Pradhan, N.; Katz, B.; Efrima, S. Synthesis of high-quality metal sulfide nanoparticles from alkyl xanthate single precursors in alkylamine solvents. J. Phys. Chem. B 2003, 107, 13843-13854. [CrossRef]

56. Efrima, S.; Pradhan, N. Xanthates and related compounds as versatile agents in colloid science. C. R. Chim. 2003, 6, 1035-1045. [CrossRef]

57. Kristl, M.; Dojer, B.; Gyergyek, S.; Kristl, J. Synthesis of nickel and cobalt sulfide nanoparticles using a low cost sonochemical method. Heliyon 2017, 3, e00273. [CrossRef] [PubMed] 